\title{
Araştırma Makalesi \\ Hibrit Enerji Sistemlerinin Şebekeden Bağımsız Bir Çiftlik Evinde Uygulanabilirliğinin Ekonomik ve Teknik Açıdan İncelenmesi
}

\author{
Sunay Türkdŏgan ${ }^{a, b^{*}}$, Serkan Dilber ${ }^{b}$, Barış Çam $^{b}$, \\ Yalova Üniversitesi, Mühendislik Fakültesi, ${ }^{a}$ Elektrik Elektronik Mühendisliği Bölümü, ${ }^{b}$ Enerji \\ Sistemleri Mühendisliği Bölümü, Yalova,Turkey
}

$\ddot{O} z$

Bu çalışmada, Yalova'nın Erikli Yaylasında bulunan bir çiftlik evinin elektriksel yük ihtiyacını karşılamak üzere şebekeden bağımsız hibrit enerji sisteminin teknik ve ekonomik açıdan uygulanabilirliği araştırılmıştır. Çiftlik evinin elektriksel yük ihtiyacı hesaplanmış, rüzgâr hızı ve güneş radyasyon verileri kullanılarak, bilgisayar yazılımı (HOMER-Hybrid Optimization Model for Electric Renewable) yardımıla hibrit enerji sistem modeli oluşturulmuştur. Hibrit enerji sisteminde iki farklı akü depolama birimleri kullanılarak teknik ve ekonomik açıdan karşılaştırılmıştır. Hibrit enerji sisteminde kurşun asit ve lityum iyon akü grupları kullanılmış ve birim enerji maliyeti ve teknik açıdan lityum iyon akü grubunun kullanılması daha mantıklı bulunmuştur. Aynı zamanda rüzgâr hızı, rüzgâr türbini rotor yüksekliği ve dizel yakıt fiyatı gibi parametreler ele alınarak hassasiyet analizleri yapılmış ve farklı olasılıklar altında hangi enerji sisteminin daha uygulanabilir olacağı ortaya konmuştur. Yapılan bu çalışma tarım-hayvancılık alanında yenilenebilir enerji kullanımını teşvik edecek olup farklı hibrit sistem alternatiflerinin de değerlendirilmesine önayak olacak örnek bir çalışma olacaktır.

Anahtar Kelimeler: Hibrit enerji sistemleri, HOMER, yenilenebilir enerji, enerji maliyeti, tarım ve hayvancilik.

\section{Economic and Technical Investigation of the Feasibility of Off-Grid Hybrid Energy Systems for a Farmhouse}

\begin{abstract}
This work investigates the technical and economic feasibility of an off-grid hybrid energy system for a farm located at Erikli plateau in Yalova, TURKEY. Electrical load demand was calculated and a hybrid energy system was designed via HOMER (Hybrid Optimization Model for Electric Renewable) program by considering the location's solar radiation and wind energy potentials. A comparative analysis for the hybrid systems with two different battery types was done to figure which system is more feasible in terms of economy and technique. The analysis result shows that the system with Lithium Ion batteries is more feasible. Moreover a number of sensitivity analyses were done by considering various wind speeds, wind turbine hub heights and diesel fuel price and as a result introduced several combinations delivering the best feasibility. This work is believed to stimulate the usage of renewable energy sources coordinately for agricultural-livestock applications and might be a good reference to urge the usage of other potential renewable energy sources.
\end{abstract}

\footnotetext{
${ }^{*}$ Sorumlu Yazar

e-mail: sunay.turkdogan@yalova.edu.tr
}

Received: 22.02 .2018

Accepted: 16.11 .2018 
Keywords: Hybrid energy systems, HOMER, renewable energy, energy price, agricultural and livestock.

\section{Giriş}

Dünyadaki nüfus artışı, şehirleşme, sanayileşme ve teknolojinin gelişmesi ile birlikte enerjiye olan gereksinim sürekli olarak artış göstermektedir. Enerji önemli bir bileşen olmakla beraber, yaşam standartlarının yükseltilmesinde büyük bir rol oynamaktadır. Enerjinin temiz, verimli ve ekonomik olarak kullanılması ülkelerin en önemli misyonudur. Ülkenin kişi başına düşen elektrik enerji tüketimi o ülkenin gelişmişlik seviyesi ile doğru orantılı olarak artmaktadır. Sürdürülebilir kalkınma için sürekli ve kaliteli bir enerjiye ihtiyaç duyulmaktadır. Günümüzde fosil kaynaklı yakıtların azalma eğilimi göstermesi ve belirli bir süre zarfı sonunda tükenecek olmasından dolayı, yenilenebilir enerji kaynaklarının kullanımına önem verilmeye başlanmıştır. Fosil kaynaklı yakıtların kullanılması küresel 1sınma ve iklim değişikliğine sebep olmakta ve dünyamızı yaşanmaz hale getirecek koşulların önünü açmaktadır. $\mathrm{Bu}$ doğrultuda yenilenebilir enerji kaynaklarının kullanımı ve bu sistemlerin geliştirilmesine yoğunluk verilmeye başlanılmıştır. Yenilenebilir enerji kaynaklarının diğer enerji kaynakları ile beraber kullanılabiliyor olması yani hibrit sistem oluşturmaları önemli bir avantaj sağlamaktadır. Hibrit enerji sistemi, yenilenebilir kaynaklı ya da fosil kaynaklı sistemlerin bir arada kullanılması ile enerji üretimi gerçekleştirmektedir. Hibrit bir enerji sisteminin performansı, çevresel koşullara bağlı olmakla birlikte, bir bölgeye özgü analiz, maliyet ve bileşenlerin boyutuna bağlıdır. Bundan dolayı bu etkenlerin araştırılması büyük ölçüde önemlidir [1]. Rüzgâr ve güneş enerjisi yenilenebilir enerji kaynakları arasında öncülük etmekle beraber bu sistemlere yönelik araştırmalar gün geçtikçe daha fazla artmaktadır. Hibrit sistemlerde kullanılan dizel jeneratörün yakıt masrafı önemli bir ekonomik parametredir. Sistemde tek başına dizel jeneratör kullanılması işletme maliyeti açısından pahalı olmakta ve gün geçtikçe yakıt maliyeti artış göstermektedir. Dizel jeneratörün, bir hibrit enerji sisteminde kullanılmasıyla bu yakıt masrafi önemli ölçüde azalma gösterecektir. Aynı zamanda gün geçtikçe rüzgâr türbini ve güneş panellerinin fiyatlarındaki düşüş, hibrit enerji sistemlerinin kullanılmasını arttırmakta ve daha da artıracağı tahmin edilmektedir [2,3]. Hayvancilık sektöründe sistem kapasitesine göre enerji ihtiyacı artış göstermektedir. Süt hayvancılığı enerji ihtiyacının fazla olduğu sektörlerden biridir ve günde en az iki defa sağım yapılmaktadır. Süt sağma sistemlerinin çalışması için fosil kaynaklı dizel jeneratör veya direkt olarak elektrik enerjisi kullanılmaktadır. Tarımsal üretim ve hayvancılık sektöründe enerji ihtiyacı oldukça önemli olup, şebekeden bağımsız uzak bölgelerde enerji ihtiyacını karşılamak amacıyla hibrit enerji sistemleri kullanımı artmaktadır ve sektörde bu sistemlerin kullanılabilirliği araştırılmaktadır. HOMER (Hybrid Optimization Model for Electric Renewables) programı kullanılarak dünyanın farklı yerlerinde çeşitli hibrit enerji sistem modelleri geliştirilmiş ve bu modeller sayesinde ilgili coğrafik bölge için en uygun maliyetli hibrit enerji sistemi bulunmuş ve farklı optimizasyonlar ve hassaslık analizleri sonucunda da olas1 durumlarda hangi enerji sisteminin daha uygulanabilir olacağı açıklığa kavuşmuştur [4-7].

$\mathrm{Bu}$ çalışmada, Yalova'nın Erikli Yaylasında bir çiftlik evinin elektriksel yük ihtiyacını karşılamak üzere şebekeden bağımsız hibrit enerji sisteminin teknik ve ekonomik açıdan uygulanabilirliği araştırılmıştır. Çiftlik evinin elektriksel yük ihtiyacı hesaplanmış, rüzgâr hızı ve güneş radyasyon verileri kullanılarak, HOMER 
vasitasıla hibrit enerji sistem modeli oluşturulmuştur. Hibrit enerji sisteminde iki farklı akü grubu kullanılarak teknik ve ekonomik açıdan karşılaştırılmıştır. Hibrit enerji sisteminde kurşun asit ve lityum iyon akü grupları kullanılmıştır. Birim enerji maliyeti ve teknik açıdan lityum iyon akü grubunun kullanıldı $\breve{g}_{1}$ hibrit enerji sisteminin daha uygulanabilir olduğu tespit edilmiştir. Uygulanabilir olan hibrit enerji sisteminin ekipmanları detaylı olarak incelenmiştir. Aynı zamanda rüzgâr hızı, rüzgâr türbini rotor yüksekliği ve dizel yakıt fiyatı gibi parametreler ele alınarak hassasiyet analizleri yapılmış ve değişik senaryolar altında en uygun maliyetli sistem tespit edilmiştir.

\section{Sistem Tanıtımı}

Yalova'nın Erikli Yaylasında kurulması planlanan bir çiftlik evinin enerji ihtiyacını karşılamak amacıyla hibrit enerji sistem tasarımı gerçekleştirilmiştir. $\mathrm{Bu}$ çiftlikte; $120 \mathrm{~m}^{2}{ }^{\prime} \mathrm{l} \mathrm{k}$ alana sahip 4 kişinin yaşayabileceği ev ve $280 \mathrm{~m}^{2}$ lik alana sahip 50 büyükbaş hayvanın yaşayabileceği ahır bulunmaktadır. Bu iki yer için iki ayrı elektrik yükü bulunmaktadır. Günlük elektrik yükleri ev ve ahır için sırasıyla 9,081 kWh ve 4,58 kWh olarak hesaplanmıştır. Toplam elektrik yükü ise 13,661 kWh olarak hesaplanmıştır. Tasarlanan çiftlik evinde enerji; aydınlatma, su pompası, süt sağma makinesi ve elektrikli ev aletleri kullanılmaktadır. Günlük elektrik tüketiminin $\% 9,1$ ' i aydınlatma, $\% 10,9$ ' u su pompası, \%17,57' si süt sağma makinesi ve $\% 62,43$ ' ü elektrikli ev aletleri tarafindan harcanmaktadır.

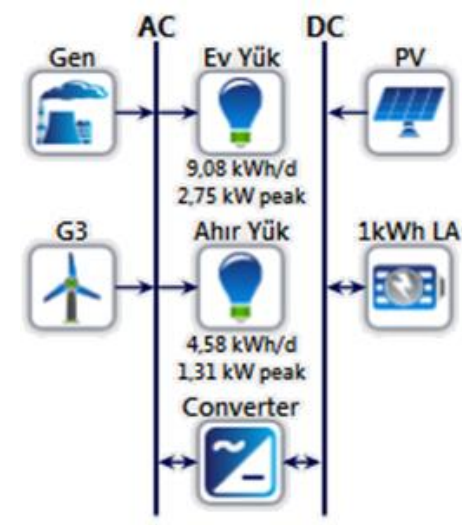

Şekil 1. Hibrit enerji sistem modeli (Gen: Dizel Jeneratör, G3: Rüzgâr tribünü, $P V$ :

Fotovoltaik Panel, $1 \mathrm{kWh}$ LA: Batarya Depolama Birimi)

Kurulması planlanan çiftlik evinin elektrik yükünü karşılamak için oluşturulan hibrit enerji sisteminin modeli Şekil 1'de görülmektedir. $\mathrm{Bu}$ sitemde ev ve ahır için iki ayrı elektrik yükü bulunmaktadır. Yük 1 ev yükünü, yük 2 ise ahır yükünü temsil eder. Hibrit enerji sisteminde elektrik ihtiyacını karşılamak için dizel jeneratör, fotovoltaik (PV) panel, rüzgâr türbini ve akü grubu bulunmaktadır. Dönüştürücü ise AC ve DC elektrik hatları arasında çift taraflı elektriksel dönüşümü gerçekleştirmektedir.

\section{Sistemin yükleri}

Çiftlik evinde ve ahırda kullanılan elektrikli ev cihazlarının güçleri ve günlük kullanım süreleri Tablo 1'de verilmektedir. Enerji tüketim değerleri güç ve günlük kullanım süresinin çarpımıyla bulunmuştur. Çiftlik evinin toplam enerji tüketimi 9,081 $\mathrm{kWh}$, ahırda ise $4,58 \mathrm{kWh}$ olarak hesaplanmıştır. 
Tablo 1. Çiftlik evinde ve ahırda kullanilan elektrikli cihazların elektriksel büyüklükleri, günlük kullanım süreleri ve tüketilen enerji miktarları.

\begin{tabular}{|c|c|c|c|}
\hline Elektrikli Ev Cihazları & Güç (W) & Günlük Kullanım Süresi (h) & Enerji Tüketimi (Wh) \\
\hline Lamba (6 adet) & 23 & 4 & 552 \\
\hline Bulaşık Makinesi & 1800 & 0,5 & 900 \\
\hline Çamaşır Makinesi & 800 & 0,5 & 400 \\
\hline Buzdolab1 & 40 & 24 & 960 \\
\hline Yayık Makinesi & 200 & 1 & 200 \\
\hline Elektrik Süpürgesi & 1600 & 0,5 & 800 \\
\hline Ütü & 2200 & 0,5 & 1,100 \\
\hline TV & 100 & 4 & 400 \\
\hline Bilgisayar & 100 & 1 & 100 \\
\hline Telefon Șarj Aleti & 9 & 1 & 9 \\
\hline Elektrikli Şofben & 2000 & 1 & 2,000 \\
\hline Firn & 2000 & 0,1 & 200 \\
\hline Derin Dondurucu & 40 & 24 & 960 \\
\hline \multirow[t]{2}{*}{ Saç Kurutma Makinesi } & 1000 & 0,5 & 500 \\
\hline & & Toplam enerji tüketimi & 9,081 (kWh) \\
\hline Cihazlar & Güç (W) & $\begin{array}{c}\text { Günlük Kullanım Süresi } \\
\text { (h) }\end{array}$ & Enerji Tüketimi (Wh) \\
\hline Lamba (10 adet) & 23 & 3 & 690 \\
\hline Su Pompast (2 adet) & 745 & 1 & 1,490 \\
\hline $\begin{array}{c}\text { Süt Sağma Makinesi (2 } \\
\text { adet) }\end{array}$ & 600 & 2 & 2,400 \\
\hline & & Toplam enerji tüketimi & $4,580(\mathrm{kWh})$ \\
\hline
\end{tabular}

Çiftlik evinde günlük elektrik tüketimi sabah ve akşam saatlerinde artmaktadır. Kıș aylarında elektrik tüketimi yaz aylarına göre biraz daha fazladır. Şekil 2(a,b)'de çiftlik evi için ve Şekil 2(c,d)' de ahır için günlük ve aylık elektrik tüketim değerleri gösterilmektedir. Ahır için de elektrik tüketimi sabah ve akşam saatlerinde artmaktadir. Bunun nedeni günde iki defa olmak üzere sabah ve akşam saatlerinde sağım yapılmasıdır. Kış ve yaz aylarında elektrik tüketim değerleri pek farkl111k göstermemektedir.

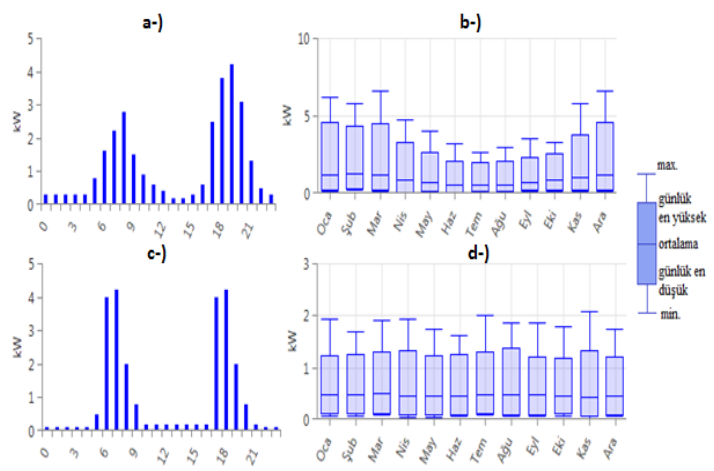

Şekil 2. Çitlik evi için oluşturulan (a) günlük ve (b) aylık yük değişimleri. Ahır için oluşturulan (c) günlük ve (d) aylık yük değişimleri.

\section{Analiz ve Yöntem}

\section{Bölgenin meteorolojik verileri}

Bölgenin solar enerji profili Şekil 3'de görülmektedir. HOMER programı bu verileri NASA (yüzey meteorolojisi ve güneş enerjisi) veri tabanından almaktadır. $\mathrm{Bu}$ veriler Yalova (40.5 enlem, 29.5 boylam) için alınmıştır.

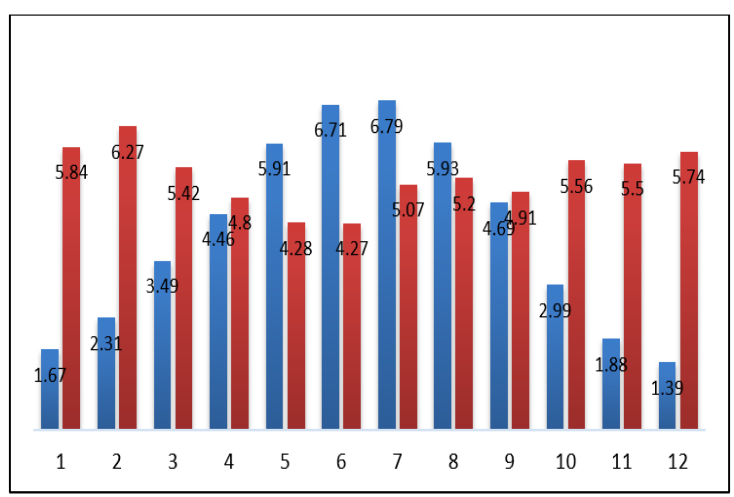

Şekil 3. Ortalama aylık güneş radyasyonu ve rüzgâr hizının (50 m'de) aylara göre değişimi. 12 aya bölünmüsş olan grafikte her aya ait iki sütun görülmekte ve bu sütunların soldakisi güneş radyasyonunu ( $\left.\mathrm{kWh} / \mathrm{m}^{2} / g \ddot{u} n\right)$ sağdakisi ise rüzgâr hızını $(\mathrm{m} / \mathrm{s})$ temsil etmektedir.

Veri tabanından alınan meteorolojik veriler, 22 yılın ortalamas1 olup, 1983-2005 yılları arasında alınan verilerdir [8]. Şekil 3 incelendiğinde yılın günlük ortalama radyasyon değeri $4,02 \mathrm{~kW} / \mathrm{m}^{2} /$ gün olduğu görülmektedir. Ayrıca yaz aylarında yüksek 1şınım şiddeti gözlemlenirken, kış aylarında yaz aylarına göre daha düşük 1şınım şiddeti gözlenmektedir. Bölgenin rüzgâr hızı profili de yine aynı grafikte (Şekil 3) görülmektedir. Rüzgâr hızının aylara göre değişimi, 10 yıllık (1983-1993) ölçülmüş verilerin ortalamasıdır [8]. Kış aylarında rüzgâr hızının artığ 1 gözlemlenirken, yaz aylarında bu değer daha düşüktür. Yillık ortalama rüzgâr hızı değeri 5,24 m/s'dir. 


\section{Hibrit enerji sisteminde kullanılan ekipmanlar}

\section{Dizel jeneratör}

Piyasada bulunan bir dizel jeneratörün $\mathrm{kW}$ başına maliyeti $250 \$$ ile $500 \$$ fiyat aralığında değişmektedir. Dizel jeneratörlerde $\mathrm{kW}$ başına maliyet değeri daha düşük güçlü kapasitedeki jeneratörler için daha yüksektir [4]. Dizel jeneratörün verimi, çıkış güç değeri artıkça artmaktadır. Simülasyonda kullanılan dizel jeneratörün verim-güç değişim grafiği Şekil 4'te gösterilmektedir. Dizel jeneratörün her litre başına açığa çıkarttı̆̆ 1 karon emisyonu HOMER programinda tanımlidir ve toplam karbon emisyonu bulunurken bu değer temel alınır.
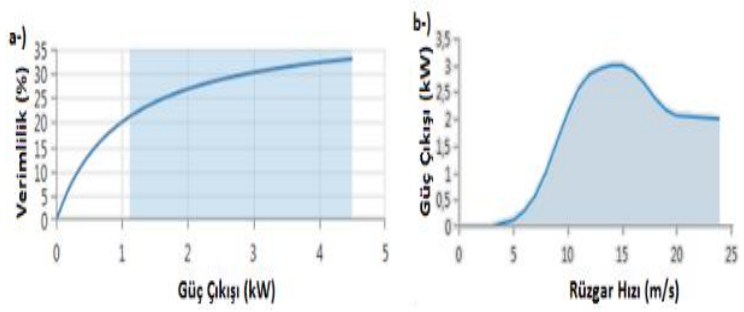

Şekil 4. (a) Dizel jeneratörün verim-gü̧̧ grafiği. (b) $3 \mathrm{~kW}$ 'llk rüzgâr türbinin rüzgâr hızına göre güç çıkış eğrisi

\section{Güneş paneli}

Güneş panelleri hibrit sistemin en önemli parçalarından biri olup üzerine düşen güneş ışınlarını herhangi bir hareketli aksam olmadan direk olarak elektrik enerjisine çevirir. Yapmış olduğumuz çalışmada PV panellerinin teknik özellikleri göz önünde bulundurulmamakta olup toplam ne kadar kapasitede PV panel kullanmamız gerektiği bulunmaktadır. Sistemde güneș paneliyle ilgili olan kısım $\mathrm{kW}$ başına maliyet fiyatıdır. PV dizilerinin kurulum maliyeti $\mathrm{kW}$ başına $4.000 \$$ ile $6.000 \$$ fiyat aralığında değişmektedir [9]. Sistemde $0,1,2,3,4$ ve $5 \mathrm{~kW}$ kapasitelerinde PV dizileri kullanılarak simülasyonlar gerçekleştirilmiş ve kullanılan bu kapasite değerlerine göre
HOMER programı ayrı ayrı benzetim yaparak en uygun kapasiteyi belirlemiştir.

\section{Rüzgâr türbini}

Rüzgâr türbininden enerji elde edilmesi, büyük ölçüde rüzgâr değişimlerine bağlıdır. Bundan dolayı rüzgâr türbinin derecelendirilmesi, ortalama elektrik yükünden daha yüksektir. $\mathrm{Bu}$ analizde $3 \mathrm{~kW}$ 'lik bir rüzgâr türbini düşünülmektedir. $\mathrm{Bu}$ türbinin maliyeti $18.000 \$$ olarak kabul edilirken, değiştirme ve bakım maliyetleri sirasıyla $14.000 \$$ ve $200 \$$ değerindedir. Rüzgâr türbinin güç çıkışı rüzgâr hızına bağlıdır ve kullanılan türbin için Şekil 4' te gösterildiği gibidir. Rüzgâr hızı belirli bir seviyenin üzerindeyken rüzgâr türbini güç üretmeye başlar ve rüzgâr hızı belli bir seviyeyi aştığında rüzgâr türbini çalışmayı durdurarak mekanik aksanların zarar görmesini engeller.

\section{Akü grubu}

Akü grubu yedekleme sistemi olarak kullanılır. Bu sistem ayrıca yük boyunca gerilim değerini sabit tutar. Sistem modellenirken kurşun asit ve lityum iyon pilleri için ayrı simülasyonlar gerçekleştirilmiştir. Akü gurubu seri/paralel konfigürasyonda sıralanmış akülerinden oluşur. Piyasada bir kurşun asit akünün alım maliyeti $300 \$$, değiştirme maliyeti ise $250 \$$, lityum iyon pillinin alım maliyeti $600 \$$, değiştirme maliyeti ise $550 \$$ değerinde olduğu saptanmıştır.

Tablo 2. Akü cinsine göre elektriksel özellikler

\begin{tabular}{|c|c|c|}
\hline Akü cinsi = & $\begin{array}{c}\text { Kurşun } \\
\text { Asit }\end{array}$ & $\begin{array}{c}\text { Lityum } \\
\text { Iyon }\end{array}$ \\
\hline Nominal voltaj (V) & 12 & 6 \\
\hline Max. șarj akımı (A) & 16,7 & 167 \\
\hline Max. desarj akımı (A) & 24,3 & 500 \\
\hline İlk şarj durumu (\%) & 100 & 100 \\
\hline Minimum şarj durumu & 40 & 20 \\
\hline $\begin{array}{c}\text { (\%) } \\
\text { Omür (yıl) }\end{array}$ & 10 & 15 \\
\hline
\end{tabular}




\section{Dönüş̧ürücü}

AC ve DC elektrik enerjisinin akışını sağlamak ve sistemi korumak için güç elektronik dönüştürücüsüne (konvertör) ihtiyaç vardır. $1 \mathrm{~kW}$ 'lık sistem için kurulum ve değiştirme maliyeti sirasıyla $700 \$$ ve $500 \$$ olarak alınmıştır. Sistemde 0, 1, 2, 3, 4 ve $5 \mathrm{~kW}$ kapasitelerinde dönüştürücüler kullanılarak simülasyonlar gerçekleştirilmiştir.

\section{Simülasyon aracı}

Simülasyon aracı olarak kullanılan HOMER yazlımı, hibrit enerji sisteminin bileşenlerinin seçimi ve boyutlandırılması için kullanılmıştır. HOMER yazılımının temel yeteneği, bir güç sisteminin uzun vadeli çalışmasını simüle etmektir. Simülasyon sürecinde yazılım, sistemin optimizasyonu, hassasiyet analizi, belirli sistem parametreleriyle çeşitli sistemlerin kombinasyonunu ve işletme stratejisi gibi birçok kalemde bilgi vermektedir [4]. HOMER yazılımı kullanıcı tarafindan belirlenen hibrit sistemlerin tüm kombinasyonlarını simüle eder. Uygulanabilir olmayan tüm kombinasyonları elimine eder ve mevcut maliyetin artmasına göre uygulanabilir sistemlerin siralamasinı yapar. Ayrica optimal bir sistem türünün tanımlamak için hassaslık değişkenlerine karşın bir dizi parametrelerin belirlenmesine izin verir.

\section{Simülasyon Modeli}

HOMER yazılımı ile Şekil 1' de görüldüğü gibi bir simülasyon modeli oluşturulmuştur. Modelde evin günlük elektrik yükü $9,08 \mathrm{kWh}$ olup, tepe gücü $2,75 \mathrm{~kW}$ değerindedir. Diğer yük olan ahırın elektrik yükü günlük 4,58 kWh olup, tepe gücü $1,31 \mathrm{~kW}$ değerindedir. $\mathrm{Bu}$ elektrik yüklerinin karşılanması için kullanılması gereken en verimli enerji sistemleri simülasyon aracımızın optimizasyon özelliği ile bulunmuştur. Simülasyon, ekipmanların farklı kapasitelerine göre gerçekleştirilmiştir (Tablo 3). Ayrıca simülasyonda hassasiyet analizi yapılırken, türbin gövde yüksekliği, ortalama rüzgâr hızı ve dizel yakıt fiyatı değişimleri göz önüne alınmıştır (Tablo 4). $\mathrm{Bu}$ hassasiyet parametrelerinin yanında akü cinsine göre de simülasyon gerçekleştirilmiştir. Hibrit enerji sistemlerinin analizi, optimizasyonu ve ekonomileri değerlendirilmiştir. Gerçekleştirilen simülasyonlar iki ayrı akü grubuyla gerçekleştirilmiştir. Birinci simülasyon akü gruplarının lityum iyon olduğu hibrit sistem, ikincisi ise kurşun asit olduğu sistemdir. Akü ve dizel jeneratörün sayıs1/kapasitelerinde sinırlama getirilmemiş ve HOMER yazılımı tarafindan uygun say1/kapasite belirlenmiştir.

Tablo 3. Simülasyonda kullanılan ekipmanların kapasite sintrlart.

\begin{tabular}{|c|c|c|c|}
\hline & \multicolumn{3}{|c|}{ Bileşenler } \\
\hline & PV (kW) & $\begin{array}{c}\text { Rüzgâr Türbini } \\
\text { (adet) }\end{array}$ & $\begin{array}{c}\text { Dönüştürücü } \\
(\mathbf{k W})\end{array}$ \\
\hline & 0 & 0 & 0 \\
\hline \multirow{2}{*}{ Boyutları/Sayıları } & 1 & 1 & 1 \\
\hline & 2 & 2 & 2 \\
\hline & 3 & & 3 \\
\hline & 5 & & 4 \\
\hline
\end{tabular}

Tablo 4. Hassasiyet analizde kullanılan değiskenler.

\begin{tabular}{|c|c|c|c|}
\hline & $\begin{array}{c}\text { Dizel yakıt } \\
\text { fiyatı (\$/L) }\end{array}$ & $\begin{array}{c}\text { Türbin } \\
\text { gövde } \\
\text { yüksekliği } \\
\text { (m) }\end{array}$ & $\begin{array}{c}\text { Rüzgâr } \\
\text { hızı (m/s) }\end{array}$ \\
\hline \multirow{2}{*}{ Değerler } & 1,35 & 17 & 5,238 \\
\hline & 1,40 & 20 & 5,500 \\
\hline & 1,45 & 25 & 6,000 \\
\hline & 1,50 & 30 & 6,500 \\
\hline & 1,55 & & \\
\hline
\end{tabular}

\section{Simülasyonda kullantlan ekipmanların maliyet değerleri}

Simülasyonda

kullanılan ekipmanların alım, değiştirme ve işletme maliyetleriyle ömürleri kullanıcı tarafından girilmiştir. Sistemin çalışma ömrü 25 yıl 
kabul edilerek, simülasyonlar gerçekleştirilmiştir. Tablo 5'te ekipmanların maliyet değerleri verilmektedir. Yapılan tüm simülasyonlar bu maliyet tablosuna göre değerlendirilmiştir.

Tablo 5. Simülasyonda kullanılan ekipmanların maliyet değerleri.

\begin{tabular}{|c|c|c|c|c|}
\hline Ekipman & $\begin{array}{c}\text { Basslangıc } \\
\text { Maliyeti (\$) }\end{array}$ & $\begin{array}{c}\text { Değiștirme } \\
\text { Maliyeti (\$) }\end{array}$ & $\begin{array}{c}\text { İşletme } \\
\text { Maliyeti } \\
\text { (\$/yl) }\end{array}$ & $\begin{array}{c}\text { Ömür } \\
\text { (yl) }\end{array}$ \\
\hline $\begin{array}{c}\text { PV(\$/kW) } \\
\text { Rüzgâr Türbini }\end{array}$ & 5.000 & 3.000 & 50 & 25 \\
\hline $\begin{array}{c}\text { (\$/adet) } \\
\text { Konverter(\$/kW) }\end{array}$ & 18.000 & 14.000 & 200 & 20 \\
\hline $\begin{array}{c}\text { Akü(\$/kW)- } \\
\text { Kurşun Asit }\end{array}$ & 300 & 500 & 0 & 15 \\
\hline $\begin{array}{c}\text { Akü(\$/kW)- } \\
\text { Lityum İyon }\end{array}$ & 600 & 550 & 10 & 10 \\
\hline Jeneratör(\$/kW) & 500 & 500 & 0,03 & $15.000 \mathrm{hr}$ \\
\hline
\end{tabular}

\section{Simülasyonda kullanılan ekonomik parametreler}

Simülasyonun daha gerçekçi yapılabilmesi için ekonomik değerlerin hesaplanmasinda bazı parametrelerin girilmesi gerekmektedir. Faiz oranı ve enflasyon oranı gibi proje ömrünce maliyeti etkileyecek parametrelerin belirlenmesi gerekmektedir. Faiz oranı bir ekonomik varlığın bugünkü değerinin hesaplanmasinda kullanılan oranı iken, enflasyon oranı ise alım gücünü ifade etmektedir. Simülasyonda kullanılan faiz oran $1 \% 8$, enflasyon oran 1 ise $\% 11$ 'dir [10]. Dizel jeneratör hibrit sistemde kullanılması ön görülen fosil kaynaklı tek güç sistemidir. Dizel yakıt fiyatının dolar üzerinden artışının göz önünde bulundurulması ve bu olası artışın sistem maliyetini doğrudan etkileyeceğinden bu ekonomik parametrenin belirli sınırlar içerisinde belirlenmesi gerekmektedir. Dizel yakıtın litre fiyatı 5,7 $€$ olarak alınmıştır ( $1 \$=3,8$ $€$ değerindedir) [11,12].

\section{Analiz Sonuçları}

Akü seçimine göre analiz sonuçları (Kurşun asit-Lityum iyon) (Analysis result based on the battery type)

HOMER yazılımı ile elde edilen analizlerde hassasiyet parametreleri doğrultusunda birçok veriye ulaşılmıştır. HOMER yazılımı ile temel parametreler (türbin gövde yüksekliği $17 \mathrm{~m}$, dizel yakıt maliyeti $1,35 \$ / \mathrm{L}$, ortalama rüzgâr hızı $5.24 \mathrm{~m} / \mathrm{s}$ ) doğrultusunda elde edilen simülasyon değerleri aşağıda tablolar halinde verilmiştir. Burada temel parametreler olarak tanımlanan değerler sistem için minimum değerlerdir. Örneğin, türbin gövde yüksekliği türbin dizaynından dolayı en az $17 \mathrm{~m}$ yüksekliğe sahip bir kuleye yerleştirilmelidir. Ayrıca HOMER yazılımı yıllık rüzgâr verilerini NASA'dan alarak bu yıllık rüzgâr hızı ölçümlerinden ortalama bir değer ile çözüm yapmaktadır. Ortalama rüzgâr hızı değeri $5,24 \mathrm{~m} / \mathrm{s}$ olarak yazılım tarafından bulunmuştur. Aynı zamanda dizel yakıt litre fiyatı 1,35 \$ olarak alınan bu değer güncel olup, sistem simülasyonunda en minimum dizel yakıt sarfiyatı değeridir. 
Tablo 6. Akü grubu (a) Lityum İyon ve (b) Kurşun Asit olan hibrit sistemlerin simülasyon sonuçlarl (en uygun ilk altı sistem). (PV: Fotovoltaik (FV), G3: Rüzgar jeneratörü, Gen: Dizel jeneratör, $1 \mathrm{kWh}$ LI veya Pb Acid: $1 \mathrm{kWh}$ kapasitesinde Lityum Iyon veya Kurşun Asit batarya, Converter: $A C \nleftarrow \rightarrow D C$ konvertör, COE: Birim enerji maliyeti, NPC: Net şimdiki fiyat, Operating Cost: Operasyon maliyeti, Initial Cost: Illk atırım maliyeti, Ren. Frac.: Sistemin yenilenebilir olma yüzdesi.)

\begin{tabular}{|c|c|c|c|c|c|c|c|c|c|c|c|c|c|c|}
\hline m & 个 & E. & 远 & ${ }_{(\mathrm{kW})}^{\mathrm{PV}} \mathrm{P}$ & G3 $\nabla$ & $\begin{array}{l}\text { Gen } \checkmark \\
(\mathrm{kW})\end{array}$ & $1 \mathrm{kWh} \cup \nabla$ & $\begin{array}{c}\text { Converter } \nabla \\
(\mathrm{kW})\end{array}$ & {$[8$} & ${ }_{(\$)}^{\mathrm{COE}}(\nabla$ & $\begin{array}{c}N P C \\
(\$)\end{array}$ & $\begin{array}{c}\text { Operating cost } \checkmark \\
\text { (\$) }\end{array}$ & $\begin{array}{c}\text { Initial capital } \\
\text { (\$) }\end{array}$ & $\begin{array}{c}\text { Ren Frac } \\
(\%)\end{array}$ \\
\hline 需 & & E & $\boldsymbol{Z}$ & 5,00 & & 4,50 & 18 & 3,00 & $\mathrm{CC}$ & $0,446 s$ & $80.953 \mathrm{~S}$ & $1.396 \mathrm{~S}$ & $30.150 \mathrm{~S}$ & 60,7 \\
\hline PT & $\uparrow$ & E & 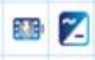 & 5,00 & 1 & 4,50 & 16 & 3,00 & LF & $0,476 \mathrm{~S}$ & $86.437 \mathrm{~S}$ & $1.085 \mathrm{~S}$ & $46.950 \mathrm{~S}$ & 90,1 \\
\hline 4 & 个 & & $\boldsymbol{z}$ & 5,00 & 1 & & 36 & 2,00 & $\mathrm{CC}$ & $0,572 \mathrm{~S}$ & $100.734 \mathrm{~S}$ & $1.229 \mathrm{~S}$ & $56.000 \mathrm{~S}$ & 100 \\
\hline & 卜 & E & 䤓 & & 1 & 4,50 & 14 & 3,00 & $\mathrm{CC}$ & $0,672 \mathrm{~S}$ & $122.011 \mathrm{~s}$ & $2.507 \mathrm{~S}$ & $30.750 \mathrm{~S}$ & 24,4 \\
\hline & & E & $\tilde{\boldsymbol{Z}}$ & & & 4,50 & 6 & 4,00 & $\mathrm{CC}$ & $0,732 \mathrm{~s}$ & $132.869 \mathrm{~S}$ & $3.413 \mathrm{~S}$ & $8.650 \mathrm{~S}$ & 0 \\
\hline & 个 & & 酙 & & 5 & & 42 & 4,00 & $\mathrm{CC}$ & $1,20 \mathrm{~s}$ & $209.662 \mathrm{~S}$ & $2.518 \mathrm{~S}$ & $118.000 \mathrm{~s}$ & 100 \\
\hline \multicolumn{15}{|c|}{ Kurşun Asit Batarya Grubu } \\
\hline 需 & & $E$ & 중 & 5,00 & & 4,50 & 34 & 2,00 & LF & $0,515 \mathrm{~s}$ & $93.441 \mathrm{~S}$ & 1.775 s & $28.850 \mathrm{~S}$ & 71,8 \\
\hline 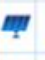 & 卜 & E & $\boldsymbol{Z}$ & 5,00 & 1 & 4,50 & 32 & 3,00 & LF & $0,548 \mathrm{~s}$ & $99.441 \mathrm{~S}$ & $1.442 S$ & $46.950 \mathrm{~S}$ & 92,1 \\
\hline \multirow{4}{*}{$\mathbf{P}$} & $\uparrow$ & & E & 4,00 & 2 & & 32 & 3,00 & $\mathrm{CC}$ & $0,649 \mathrm{~S}$ & $114.104 \mathrm{~S}$ & $1.495 \$$ & $59.700 \mathrm{~S}$ & 100 \\
\hline & $\uparrow$ & E & 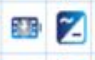 & & 1 & 4,50 & 10 & 1,00 & $\mathrm{CC}$ & $0,775 \mathrm{~S}$ & $140.595 \mathrm{~S}$ & $3.205 \mathrm{~s}$ & $23.950 \mathrm{~S}$ & 20,8 \\
\hline & & $\bar{E}$ & 죽 & & & 4,50 & 8 & 1,00 & $\mathrm{CC}$ & $0,813 \mathrm{~s}$ & $147.536 \mathrm{~S}$ & $3.906 \mathrm{~S}$ & $5.350 \mathrm{~s}$ & 0 \\
\hline & 小 & & स & & 7 & & 40 & 4,00 & $\mathrm{CC}$ & $1,45 \mathrm{~s}$ & $252.253 \mathrm{~S}$ & $3.062 \mathrm{~S}$ & $140.800 \mathrm{~S}$ & 100 \\
\hline
\end{tabular}

Simülasyon sonucunda; sistem tarafindan üretilen faydalı elektrik enerjisinin, $\mathrm{kWh}$ başına ortalama maliyetini ifade eden birim enerji maliyeti (COE) değerine göre, HOMER yazılımı tarafından sonuçlar sıralanır. COE değeri en düşük olan PV-Dizel Jeneratör-Kurşun Asit Akü hibrit enerji sistemidir (Tablo 6). Bu sistemde $5 \mathrm{~kW}$ kapasiteye sahip PV, $4,5 \mathrm{~kW}$ kapasiteye sahip dizel jeneratör ve 34 adet $1 \mathrm{kWh}$ kapasiteye sahip kurşun asit akü grubu ve $2 \mathrm{kWh}$ değerine sahip konvertör ünitelerinden oluşur. PV-Dizel JeneratörAkü hibrit enerji sistemi 28.850 \$ değerinde ilk yatırım maliyetine sahiptir.

Akü grubu Lityum iyon olan sistemlerin simülasyon sonuçları Tablo 6' nın üst grubunda görülmektedir. Simülasyon sonucunda, COE değerine göre sıralama yapıldığından, en düşük $\mathrm{COE}$ değerine sahip hibrit sistemin PV-Dizel Jeneratör-Akü hibrit enerji sistemi olduğu görülmektedir. Bu sistem $5 \mathrm{~kW}$ kapasiteye sahip PV, 4,5 kW kapasiteye sahip dizel jeneratör ve 18 adet $1 \mathrm{kWh}$ kapasiteye sahip lityum iyon akü grubu ve $3 \mathrm{kWh}$ değerine sahip konvertör ünitelerinden oluşur. PVDizel Jeneratör-Akü hibrit enerji sistemi $30.150 \$$ değerinde ilk yatırım maliyetine sahiptir.

\section{Kurşun asit ve Lityum iyon akü ünitelerinin karşılaştırılması}

HOMER yazılımı ile temel parametreler (türbin gövde yüksekliği $17 \mathrm{~m}$, dizel yakit sarfiyati $1,35 \$ / L$, ortalama rüzgâr hız1 $5.24 \mathrm{~m} / \mathrm{s}$ ) doğrultusunda elde edilen simülasyon değerleri aşağıda tablo halinde verilmiştir. Bu simülasyon değerleri iki farklı akü grubuna (Teknik özellikler için Tablo 7' ye bakınız) ait hibrit enerji sistemlerinin, COE değerine göre en minimum değerleri olan sonuçlarıdır. 
Tablo 7. Kurşun asit ve Lityum iyon akü grubuna ait hibrit sistem sonuçlart

\begin{tabular}{|c|c|c|}
\hline Akü grubu & Kurşun asit & Lityum iyon \\
\hline PV kapasitesi (kW) & 5 & 5 \\
\hline Akü sayısı & 34 & $18 \times 2$ \\
\hline Convetör (kW) & 2 & 3 \\
\hline Dizel jeneratör (kW) & 4,5 & 4,5 \\
\hline COE (\$) & 0,514 & 0,446 \\
\hline NPC (\$) & 93.440 & 80.952 \\
\hline Isşletme Maliyeti (\$) & 1.774 & 1.395 \\
\hline Illk yatirım maliyeti (\$) & 28.850 & 30.150 \\
\hline
\end{tabular}

İki farklı akü grubunun simülasyon sonuçlarına bakıldığında, ilk yatırım maliyeti yüksek olmasına karşın, kWh başına ortalama maliyeti ifade eden COE değeri daha düşük olan Lityum iyon akü grubuna sahip hibrit enerji sistemidir. Kurşun asit akü ünitelerine sahip hibrit enerji sisteminin ilk yatırım maliyeti 28.850\$ iken, kWh başına ortalama enerji birim maliyeti $0,514 \$$ değerindedir. Lityum iyon akü ünitelerine sahip, hibrit enerji sistem ise ilk yatırım maliyeti $30.150 \$$ iken, $\mathrm{kWh}$ başına ortalama enerji birim maliyeti $0,446 \$$ değerindedir. Lityum iyon akü sisteminin ilk yatırım maliyetinin yüksek olmasına karşın, işletme ve net şimdiki fiyat (NPC) değerleri daha düşüktür. Lityum iyon akülerin ömrü 15 yıl iken kurşun asit akülerin ömrü 10 yıldır (Tablo 7). Bu da doğrudan sistemin ekonomik değerlerini etkilemektedir. Ayrıca lityum iyon akülerin çıkış voltajı 6 Vollt değerindedir. Bundan dolayı $12 \mathrm{~V}$ olan sistemde kullanılması için seri/paralel elektriksel bağlantı yapılarak 12 V çıkışa sahip akü üniteleri elde edilir. 25 yıllık proje ömrü göz önüne alındığında, lityum iyon akü gruplarının bulunduğu sistem ekonomik açıdan daha karlı olacaktır. Dizel jeneratör ve PV kapasiteleri aynı olan bu iki farklı akü grubuna sahip hibrit enerji sisteminde konvertör (dönüştürücü) kapasiteleri farklı olmaktadır. Bunun sebebi ise akü gruplarının elektriksel özelliklerinden kaynaklamasıdır.

\section{Lityum iyon akü grubuna ait hibrit enerji sistemlerinin simülasyon sonuçları}

Bir önce ki simülasyon sonuçlarından anlaşılacağı gibi Lityum iyon akü grubuna sahip olan hibrit enerji sisteminin daha ekonomik olacağ görülmüştür. $\mathrm{Bu}$ sebepten dolayı lityum iyon akü grubuna ait hibrit enerji sistemlerinin simülasyon sonuçları detaylı olarak incelenmiş ve hassasiyet analizleri gerçekleştirilmiştir. Simülasyon sonuçlarından, 5 farklı sistem kombinasyonu ele alınmıştır. Bu sistemlerle ilgili teknik ve ekonomik analiz sonuçları tablolar halinde verilmiştir (Tablo 8).

Tablo 8'de farklı hibrit enerji sistemlerinin simülasyon sonuçları görülmektedir. $\mathrm{Bu}$ tabloda $\mathrm{CO}_{2}$ emisyonu açısından bakıldığında PV-Rüzgâr-Akü sisteminin hiç emisyon salınımı olmadığı ve sistemin yenilenebilir oranının $\% 100$ olduğu görülmektedir. Buna karşın elektrik yükü ihtiyacının dizel jeneratör güç sisteminden karşılanması durumunda ise y1llık olarak $12.955 \mathrm{~kg}$ değerinde $\mathrm{CO}_{2}$ emisyon salınımı gerçekleşecektir. Otonomi süresi; sistem yükünün tamamen akü gruplarından karşılanmasının süresini ifade etmektedir. En fazla otonomi süresine sahip hibrit sistem PV-Rüzgâr-Akü hibrit enerji sistemidir. Simülasyon sonuçlarından elde edilen 5 farklı hibrit enerji sisteminin maliyet değerleri Tablo 8'de verilmektedir. Sistem konfigürasyonları değiştikçe sistemin ekonomik değerlerinin değiştiği de gözlemlenmektedir. $\mathrm{Bu}$ ekonomik değişiklikler sistemde bulunan ekipmanların yatırım, işletme ve bakım maliyetlerinin değişmesinden kaynaklanmaktadır. Birim enerji maliyeti açısından bakıldığında en uygun hibrit enerji sisteminin PV-Dizel Jeneratör-Akü hibrit enerji sistemi olduğu görülmektedir (Tablo 8). Buna karşın yenilenebilir enerji oranı \%60,7 değerindedir. İlk yatırım maliyeti açısından bakıldığında dizel jeneratör güç sisteminin diğer sistemlere göre daha düşük olduğu görülür. Lakin bu durumda dizel jeneratörün yakıt sarfiyatını içeren ve periyodik bakımları kapsayan 
maliyetler sistem ömrünce (25 y1l) göz önüne alındığında COE değerinin, diğer hibrit sistemlere göre daha yüksek olduğu görülmektedir.

Tablo 8. Farklı sistem kombinasyonlarının teknik ve ekonomik analiz sonuçları

\begin{tabular}{|c|c|c|c|c|c|}
\hline Parametreler & $\begin{array}{l}\text { PV-Rüzgâr- } \\
\text { Diz el-Akü }\end{array}$ & $\begin{array}{l}\text { PV-Rüzgâr- } \\
\text { Akü }\end{array}$ & $\begin{array}{c}\text { Rüzgâr- } \\
\text { Diz el-Aküu }\end{array}$ & $\begin{array}{c}\text { PV-Dizel- } \\
\text { Akü }\end{array}$ & Dizel \\
\hline $\begin{array}{c}\text { Sistem } \\
\text { boyutlan }\end{array}$ & $\begin{array}{c}\text { PV: } 5 \mathrm{~kW} \\
\text { Rüzgâr: } 3 \mathrm{~kW} \\
\text { Dizel: } 4,5 \mathrm{~kW}\end{array}$ & $\begin{array}{c}\text { PV: } 5 \mathrm{~kW} \\
\text { Rüzgâr: } 3 \mathrm{~kW}\end{array}$ & $\begin{array}{c}\text { Rüzgâr: } 3 \mathrm{~kW} \\
\text { Dizel: } 4,5 \\
\text { kW }\end{array}$ & $\begin{array}{c}\text { PV: } 5 \mathrm{~kW} \\
\text { Dizel: } 4,5 \\
\text { kW }\end{array}$ & $\begin{array}{l}\text { Dizel: } \\
4,5 \mathrm{~kW}\end{array}$ \\
\hline Akü sayısıı & 16 & 36 & 14 & 18 & 0 \\
\hline $\begin{array}{l}\text { Sistem yükü } \\
(\mathbf{k W h} / \mathbf{y l})\end{array}$ & $4.986,27$ & $4.986,27$ & 4.986,27 & $4.986,27$ & $4.986,27$ \\
\hline $\begin{array}{c}\mathrm{CO2} \\
\text { Emisyonu } \\
(\mathrm{kg} / \mathrm{yl})\end{array}$ & 596 & 0 & 3.095 & 1.619 & 12.955 \\
\hline $\begin{array}{c}\text { Fotovoltaik } \\
(\mathrm{kWh} / \mathrm{yl})\end{array}$ & $\begin{array}{c}6.507(\% 69,4 \\
)\end{array}$ & $\begin{array}{c}6.507(\% 73,2 \\
)\end{array}$ & 0 & $6.507(76,9)$ & 0 \\
\hline $\begin{array}{c}\text { Rüzgâr } \\
\text { (kWh/yl) }\end{array}$ & $2.380(\%, 24)$ & $2.380(26,8)$ & $\begin{array}{c}2.380 \\
(\% 38,7)\end{array}$ & 0 & 0 \\
\hline $\begin{array}{c}\text { Dizel } \\
\text { jeneratör } \\
\text { (kWh/yl) }\end{array}$ & $492(\% 25,4)$ & 0 & $\begin{array}{c}3.769 \\
(\% 61,3)\end{array}$ & $\begin{array}{c}1.960 \\
(\% 23,1)\end{array}$ & 10.785 \\
\hline $\begin{array}{l}\text { Toplam enerji } \\
\text { (kWh/yl) }\end{array}$ & $9.379(\% 100)$ & $8.887(\% 100)$ & $6.149(\% 100)$ & $8.467(\% 100)$ & $\begin{array}{l}10.785 \\
(\% 100)\end{array}$ \\
\hline $\begin{array}{c}\text { Fazla Elektrik } \\
(\mathrm{kWh} / \mathrm{yl})\end{array}$ & 3.884 & 3.515 & 310 & 2.757 & 5.798 \\
\hline $\begin{array}{l}\text { Otonomi } \\
\text { süresi (h) }\end{array}$ & 25,5 & 50,6 & 19,7 & 25,3 & 0 \\
\hline $\begin{array}{c}\text { Yenilenebilir } \\
\text { oranı }(\%)\end{array}$ & 90,1 & 100 & 24,4 & 60,7 & 0 \\
\hline $\operatorname{COE}(\$)$ & 0,476 & 0,572 & 0,672 & 0,446 & 1,83 \\
\hline NPC (\$) & 86.437 & 100.734 & 122.011 & 80.953 & 33.2292 \\
\hline $\begin{array}{c}\text { İșletme } \\
\text { maliyeti (\$) }\end{array}$ & 1.085 & 1.229 & 2.507 & 1.396 & 9.068 \\
\hline $\begin{array}{c}\text { Yaturm } \\
\text { maliyeti(\$) }\end{array}$ & 46.950 & 56.000 & 30.750 & 30.150 & 2.250 \\
\hline
\end{tabular}

Birim enerji maliyeti en düşük olan hibrit enerji sisteminin (PV- Dizel Jeneratör Akü) incelenmesi

Simülasyon sonuçları doğrultusunda $\mathrm{kW}$ başına en düşük maliyet değerine sahip olan hibrit enerji sisteminin teknik ve elektriksel özellikleri incelenmiştir. $\mathrm{Bu}$ sistem PV-Dizel Jeneratör-Akü hibrit enerji sistemidir. Bu sistem $5 \mathrm{~kW}$ kapasiteye sahip PV, 4,5 kW kapasiteye sahip dizel jeneratör, 18 adet $1 \mathrm{kWh}$ kapasiteye sahip lityum iyon akü grubu ve $3 \mathrm{kWh}$ değerine sahip konvertör ünitelerinden oluşur (Tablo 8).

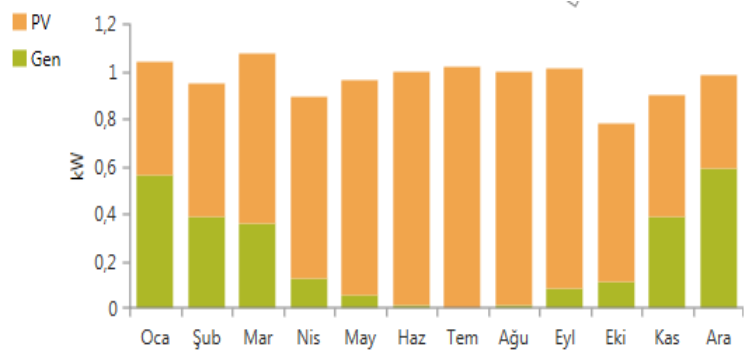

Şekil 5. PV-Dizel Jeneratör-Akü hibrit enerji sisteminin aylık güç üretim payları

Şekil 5' te en düşük yatırım ve enerji birim maliyetine sahip olan PV-Dizel Jeneratör-Akü hibrit enerji sisteminin aylık olarak üretim paylarının bir sene içerisindeki değişimi görülmektedir. Kış aylarında güneş 1şınım şiddetinin az olduğu ve bundan dolayı PV kapasitenin yanında dizel jeneratöründe yük ihtiyacını karşılamak için devreye girdiği görülmektedir. Buna karşın yaz aylarında PV güç kapasitesi yeterli olduğundan dizel jeneratörün devreye girmesine gerek kalmamıştır. Yaz aylarında ise sistem sadece PV/Akü üniteleriyle enerji ihtiyacını karşılamıştır. PV-Dizel Jeneratör-Akü hibrit enerji sisteminin y1llık üretim payları PV ve dizel jeneratör için sırasıyla şu şekildedir; Enerji (kWh/yıl): 6.507 / 1.96. PV / Dizel Jeneratör / Akü hibrit enerji sisteminin y1llı enerji üretimi 8,467 MWh/yıl'dır. Bu değerin \%76,9'si PV/Akü sisteminden üretilirken, $\% 23,1$ 'i ise dizel jeneratör tarafından üretilmektedir.

Şekil 6'da PV/Dizel Jeneratör/Akü hibrit enerji sisteminde kullanılan akü grubunun yıl içerisindeki şarj durumunu belirten grafik görülmektedir. Bu grafik incelendiğinde akü grubu şarj durumunun çoğunlukla \% 95-50 arasında olduğu gözlenmektedir. Ayrıca akü grubunun şarj durumu gün içerisinde 11:00 ve 18:00 saatleri arasında \%80-100 oranında dolu olduğu görülmektedir. Lityum iyon akünün deşarj derinliği en fazla \% 20 olduğundan bu değerden aşağıda bir değer grafikte görülmemektedir. 


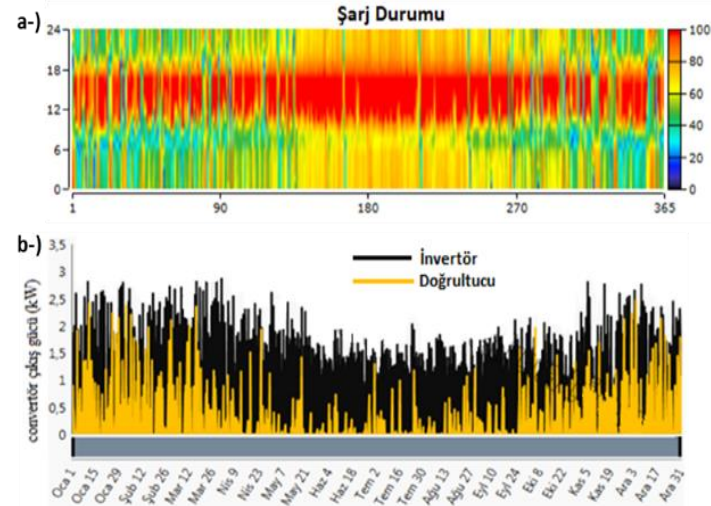

Şekil 6. (a) Lityum iyon tipi akü grubunun yıllık şarj durumu. (b) Invertör ve doğrultucunun yıllık güç çıkış değişimi.

Tablo 9. Konvertörün (invertör-doğrultucu) elektriksel özellikleri

\begin{tabular}{|l|c|c|c|}
\cline { 2 - 4 } \multicolumn{1}{c|}{} & İnvertör & Doğrultucu & Brimler \\
\hline Kapasite & 3 & 3 & $\mathrm{~kW}$ \\
\hline Ortalama çııș & 0,504 & 0,143 & $\mathrm{~kW}$ \\
\hline Minimum çııș & 0 & 0 & $\mathrm{~kW}$ \\
\hline Maksimum çıkıș & 2,72 & 3 & $\mathrm{~kW}$ \\
\hline Kapasite oranı & 16,8 & 4,77 & $\%$ \\
\hline Çalışma saatleri & 8285 & 471 & $\mathrm{kWh} / \mathrm{yl} 1$ \\
\hline Enerji çııışı & 4419 & 1253 & $\mathrm{kWh} / \mathrm{yll}$ \\
\hline Enerji giriși & 4652 & 1392 & $\mathrm{kWh} / \mathrm{yll}$ \\
\hline Kayıplar & 233 & 139 & $\mathrm{kWh} / \mathrm{yl} 1$ \\
\hline Verimlilik & 95 & 90 & $\%$ \\
\hline
\end{tabular}

Tablo 9' da PV/Dizel Jeneratör/Akü hibrit enerji sisteminde kullanılan invertör ve doğrultucunun elektriksel büyüklükleri
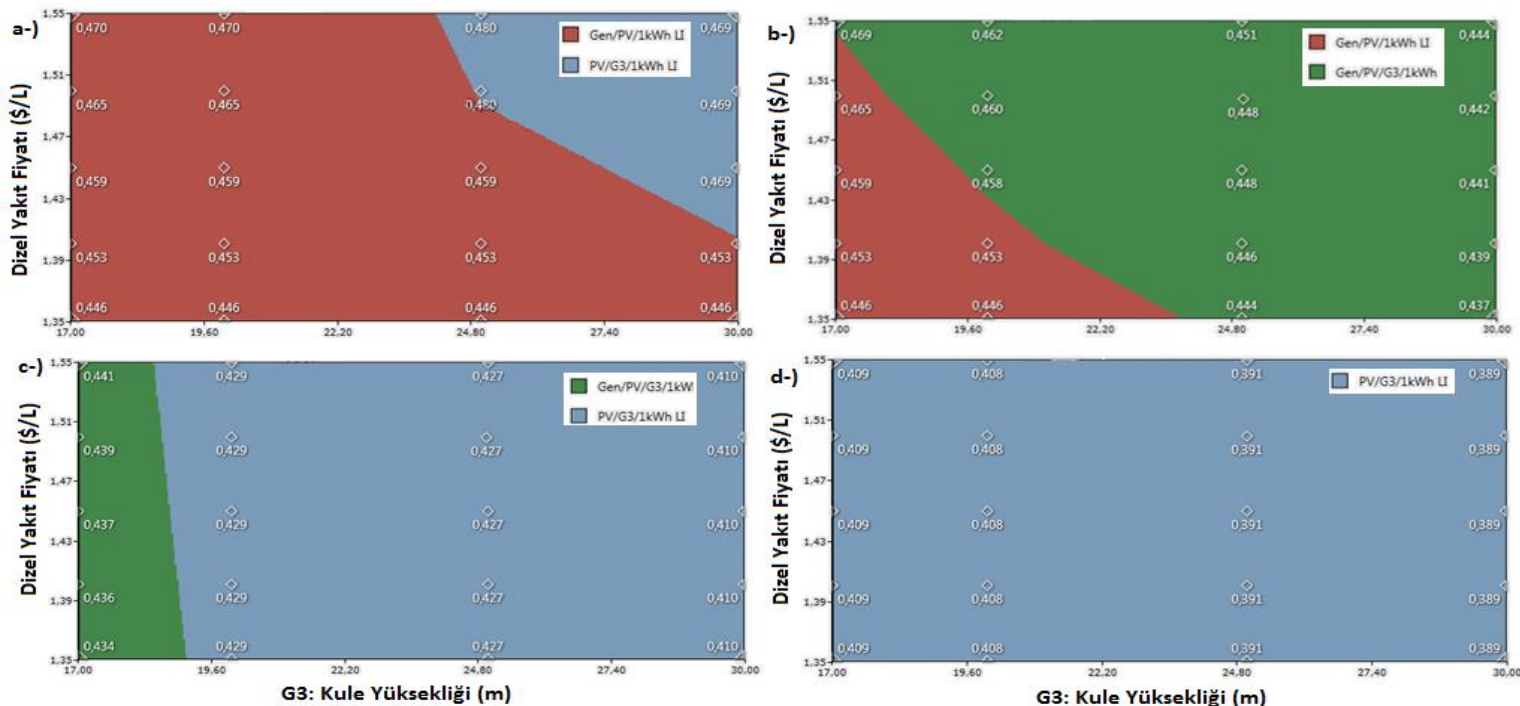

Şekil 7. Hassasiyet parametreleriyle hibrit enerji sistem konfigürasyonunun değişimi. Rüzgar ortalama hizl (a) $5.24 \mathrm{~m} / \mathrm{s}$, (b) $5.5 \mathrm{~m} / \mathrm{s}$, (c) $6 \mathrm{~m} / \mathrm{s}$, ve (d) $6.5 \mathrm{~m} / \mathrm{s}$. 
Șekil 7(a), 7(b), (7c) ve 7(d)' de sırasıyla ortalama rüzgâr hızının $5,24 \mathrm{~m} / \mathrm{s}$ (mevcut durum hizı), $5.5 \mathrm{~m} / \mathrm{s}, 6 \mathrm{~m} / \mathrm{s}$, ve 6.5 $\mathrm{m} / \mathrm{s}$ olduğu hibrit enerji sistemlerinin dizel yakıt sarfiyatı ve türbin kule yüksekliğine bağlı değişim grafikleri görülmektedir. Ayrıca bu grafiklerde birim enerji maliyet değerleri de gösterilmektedir. Şekil 7(a) incelendiğinde iki farklı hibrit enerji sistem modeli görülmektedir. Jeneratör/PV/Akü ve PV/Rüzgâr/Akü hibrit enerji sistemleridir. Jeneratör/PV/Akü hibrit enerji sisteminde dizel yakıtın fiyatı artıkça sistemin birim enerji maliyetinin arttığ görülmektedir. Aynı zamanda rüzgâr türbini rotor yüksekliğinin 25 metreden sonra ve dizel yakıt litre fiyatının 1,50 \$'a ulaştığında Jeneratör/PV/Akü hibrit enerji sisteminin değil, PV/Rüzgâr/Akü hibrit enerji sisteminin daha uygun olduğu görülmektedir. Şekil 7(b) incelendiğinde 2 farkl1 hibrit enerji sistem modeli görülmektedir. Bunlar, Jeneratör/PV/Akü ve Jeneratör/PV/Rüzgâr/Akü hibrit enerji sistemleridir. Ortalama rüzgâr hızının artması ile sistem konfigürasyonu değişmiştir. Şekil 7(a)' da Jeneratör/PV/Akü ve PV/Rüzgâr/Akü hibrit enerji sistemleri görülürken, Şekil 7(b)' de Jeneratör/PV/Akü ve Jeneratör/PV/Rüzgâr/Akü hibrit enerji sistem modelleri görülmektedir. $\mathrm{Bu}$ da rüzgâr hızının değişimi o bölge için kurulacak sistem modelinin belirlenmesinde önemli bir rol oynadığını göstermektedir. Şekil 7(c)' de yine 2 farklı hibrit enerji sistem modeli görülmektedir. Dizel Jeneratör/PV/Rüzgâr/Akü ve PV/Rüzgâr/Akü hibrit enerji sistemleridir. Ortalama rüzgâr hızının artmasıyla rüzgâr türbinini içeren hibrit sistemlerin daha da çok uygulanabilir olduğu görülmektedir. Aynı zamanda birim enerji maliyetinin de azalmasına neden olmuştur. Şekil 7(b)' de $0,437 \$$ en düşük enerji maliyetine sahip olan Jeneratör/PV/Rüzgâr/Akü hibrit enerji sistemi iken, Şekil 7(c)' de ise 0,410\$ enerji birim maliyetine sahip PV/Rüzgâr/Akü hibrit enerji sistemidir. Minimum türbin rotor yüksekliği 17 metredir. Bu değere sahip olan bir sitemin yerine türbin yüksekliği 20 metre olan bir hibrit enerji sistemi seçildiğinde sistemin dizel jeneratörden bağımlılığı kalkar ve dizel yakıt fiyat değişiminden etkilenmeyecek daha düşük enerji maliyetli bir sistem açığa çıkar. Şekil 7(d)' de tek bir hibrit enerji sistem modeli görülmektedir. $\mathrm{Bu}$ da PV/Rüzgâr/Akü hibrit enerji sistemidir. Şekil 7(d)' deki grafik incelendiğinde türbin rotor yüksekliğinin değişimi sadece enerji birim maliyetini etkilemektedir. Sistemde dizel jeneratör olmadığından yakıt fiyatı artışlarından etkilenmemektedir.

\section{Sonuç Ve Öneriler}

$\mathrm{Bu}$ çalışmada HOMER yazılımı kullanılarak şebekenden bağımsız hibrit enerji sistemi için birçok farklı sistem alternatifleri simüle edilmiştir. Hibrit enerji sisteminde iki farklı akü grubu kullanılarak teknik ve ekonomik açıdan karş1laştırılmıştır. Hibrit enerji sisteminde kurşun asit ve lityum iyon akü grupları kullanılmış olup birim enerji maliyeti ve teknik açıdan lityum iyon akü grubunun kullanıldığ 1 hibrit enerji sisteminin bu çalışma için daha uygulanabilir olduğu tespit edilmiştir.

$\mathrm{Bu}$ bağlamda Lityum Asit akü grubuna sahip olan hibrit enerji sistemleri detaylı olarak incelenmiş ve uygulanabilir olan sistemler birim enerji maliyeti ve net şimdiki değer göz önüne alınarak sıralanmıştır. $\mathrm{Bu}$ çalışma sonucunda numaralandırılmış şu sistem konfigürasyonları karşılaştırılmıştır; 1-) PV/Rüzgâr/Dizel jeneratör/Akü hibrit enerji sistemi, 2-) PV/Rüzgâr/Akü hibrit enerji sistemi, 3-) PV/Dizel jeneratör/Akü hibrit enerji sistemi, 4-) Rüzgâr/Dizel jeneratör hibrit enerji sistemi, 5-) Dizel jeneratör güç sistemi. $\mathrm{Bu}$ sistem konfigürasyonlarından enerji birim maliyeti en düşük olan sistemin PV/Dizel 
jeneratör/Akü hibrit enerji sisteminin olduğu saptanmıştır. En yüksek enerji birim maliyetine sahip sistemse Dizel jeneratör güç sistemi olduğu belirlenmiştir. Uygulanabilirliği en yüksek olan sistemin ilk yatırım maliyeti $30.150 \$$, işletme maliyeti $1.309 \$$, birim enerji maliyeti $0,446 \$$ ve proje ömrünce sistemin net bugünkü maliyeti $80.953 \$$ olduğu belirlenmiştir. $\mathrm{Bu}$ sistem $5 \mathrm{~kW}$ kapasiteye sahip PV, 4,5 kW kapasiteye sahip dizel jeneratör ve 18 adet $1 \mathrm{kWh}$ kapasiteye sahip akü grubu ve $3 \mathrm{kWh}$ değerine sahip konvertör ünitelerinden oluşmaktadır.

Yenilenebilir kaynaklı ve fosil kaynaklı hibrit sistemlerinin kullanılması ile $\mathrm{CO}_{2}$ emisyonu azalmaktadır. Dizel güç sistemi fosil kaynaklı güç sistemi olup, yıllık $10.785 \quad \mathrm{kWh}$ elektrik enerjisi üretmesine karşılık yılda 19.955 kg değerine sahip emisyon salınımı gerçekleştirmektedir. PV/Dizel jeneratör/Akü hibrit enerji sisteminin kullanılmasıyla, dizel jeneratörün yıllık $1.960 \mathrm{kWh}$ enerji üreterek emisyon değeri y1lda $1.619 \mathrm{~kg}$ değerine düşmektedir. PV/Dizel jeneratör/Akü hibrit enerji sisteminin kullanılmasıyla, yıllık olarak çevreye salınacak olan $18.336 \mathrm{~kg} \quad \mathrm{CO}_{2}$ emisyonunun önüne geçilmiş olunacaktır.

Ortalama rüzgâr hızı, rüzgâr türbini rotor yüksekliği ve dizel yakıt fiyatı gibi parametreler ele alınarak hassasiyet analizi yapılmıştır. $\mathrm{Bu}$ analizler sonucunda ortalama rüzgâr hızının artması ile rüzgâr türbinin hibrit enerji sistemlerinde uygulanabilirliği daha da artmaktadır. Dizel yakıt fiyatının $1,35 \$ / \mathrm{L}$, türbin gövde yüksekliğinin $17 \mathrm{~m}$ olmak şartıyla, ortalama rüzgâr hızının; $5,24 \mathrm{~m} / \mathrm{s}$ olduğunda birim enerji maliyeti $0,446 \$, 5,5 \mathrm{~m} / \mathrm{s}$ olduğunda $0,446 \$, 6 \mathrm{~m} / \mathrm{s}$ saniye olduğunda 0,434 ve $6,5 \mathrm{~m} / \mathrm{s}$ olduğunda $0,409 \$$ olduğu belirlenmiştir. Yani ortalama rüzgâr hızının artması ile birim enerji maliyeti düşüş göstermekte ve sistem konfigürasyonu değişmektedir (Tablo 7' ye bakınız). Aynı zamanda türbin rotor yüksekliğinin ve dizel yakıt sarfiyatının değişimi sistem konfigürasyonunun değişimine sebep olmaktadır.

Yenilenebilir enerji kaynaklı sistemlerinin kurulmadan önce fizibilite çalışmalarının ciddi bir şekilde yapılması gerekmektedir. Bunu için sistem kurulmadan önce o bölgenin güneş ve rüzgâr enerji potansiyelinin belirlenmesi gereklidir. Aynı zamanda ihtiyaç olan elektrik yükünün detaylıca belirlenmesi de önemli bir unsur teşkil etmektedir. Hibrit enerji sistemleri, bölgenin meteorolojik verileri ve sistemin elektrik yükünün değişimi doğrultusunda, sistemlerin konfigürasyonu değişmesiyle birlikte ekonomik açıdan da değişiklikler göstermektedir. $\mathrm{Bu}$ nedenle bu çalışmada yapıldığı gibi detaylı bir analiz gerektirmektedir. $\mathrm{Bu}$ çalışmada, yenilenebilir ve fosil kaynaklı enerjilerin, sistem konfigürasyonları ele alınmış ve en uygun çözüm bulunmuştur. Daha verimli ve ekonomik sistemlerin bulunabilmesi için, o bölgedeki jeotermal, hidrolik ve biyokütle gibi yenilenebilir enerji kaynaklarından da yararlanılması gerekmektedir.

\section{Kaynaklar}

[1] Habib, M.A., Said, El-Hadidy S.A.M., Al-Zaharna, Optimization procedure of a hybrid photovoltaic wind energy system, Energy, Vol. 24, 919-929, (1999).

[2] Ernest, F.B., Matthew, A., Feasibility of solar technology adoption: A case study on Tennessee's poultry industry, Renewable Energy, 34, 3, 748-754, (2009).

[3] Öztürk, H.H., Yaşar, B., Eren, Tarımda Enerji Kullanımı ve Yenilenebilir Enerji Kaynakları, Türkiye Ziraat Mühendisliği VII. Teknik Kongresi, Ankara, (2010)

[4] Khan, M.J., Iqbal, M.T., Pre-feasibility study of stand-alone hybrid energy systems for applications in Newfoundland, 
Renewable Energy, 835-854, Canada, (2005).

[5] Yıldız, M., Bingöl, F., Küçük ve mikro ölçekli enerji yatırımı için hibrit enerji modeli, 4. İzmir Rüzgâr Sempozyumu, İzmir, (2017).

[6] Nema, P., Nema, R.K., Rangekar, S., $\mathrm{Pv}$-solar/wind hybrid energy system for GSM/CDMA type mobile telephony base station, Energry And Environment, 1, 2 , 359- 366, İndia, (2010).

[7] Ngan, M.S., Tan, C.W., Assessment of economic viability for $\mathrm{PV} / \mathrm{wind} /$ diesel hybrid enegry system in southern Peninsular Malaysia, Renewable and Sustainable Energy Reviews, Malaysia, 634-647, (2012).

[8] NASA, Surface Meteorology and Solar Energy, https://eosweb.larc.nasa.gov/cgibin/sse/grid.cgi? \&num=210131\&lat=40\&s ubmit=Gnder $\&$ hgt $=100 \& v e g=17 \&$ sitelev $=$ 600\&email=skip@larc.nasa.gov\&p=grid_i $\mathrm{d} \&$ step $=2 \&$ lon $=29,(22.12 .2017)$.

[9] Ashok S., Optşmized model for communinty based-Hybrid Energy systems, Renewable Energy, 1155-1164, (2007).

[10] TCMB Türkiye Cumhuriyet Merkez Bankası, http://www.tcmb.gov.tr/wps/wcm/connect/ tcmb+tr/tcmb+tr/main+menu/para+politika si/fiyat+istikrari/enflasyon+raporu, (16.12.2017).

[11] TCMB Türkiye Cumhuriyet Merkez Bankası, https://www.turkiye.gov.tr/dovizkurlari, (16.12.2017).

[12] Shell Türkiye Akaryakıt Satış Fiyatları, http://www.shell.com.tr/motorists/shellfuels/ akaryakit-pompa-satis-fiyatlari.html, (16.12.2017). 